\title{
ENFERMAGEM EM SAÚDE PÚBLICA: UMA PROPOSTA ARTICULANDO ENSINO, PESQUISA, ESTÁGIO E EXTENSÃO
}

\author{
Aldevina Maria dos Santos ${ }^{1}$ \\ Lícia Maria de Oliveira Pinho ${ }^{2}$ \\ Marta Carvalho Loures \\ Raquel Aparecida Marra da Madeira Freitas
}

\section{INTRODUÇÃO}

Na sociedade brasileira contemporânea, "pós-moderna", globalizada, "internetizada", o neoliberalismo promove uma reestruturação social, de modo a garantir determinadas rupturas e perpetuar determinadas continuidades como, por exemplo, a capacidade do capitalismo de explorar e lucrar com as desigualdades sociais. Particularmente no caso da saúde, a política de diminuição das responsabilidades do Estado tem favorecido a privatização dos serviços. Um dos sinais mais eviA enfermagem, entendida como uma prática social, carregada de valores e contradições mas, sobretudo, de um compromisso com a emancipação humana para a vida e a saúde, não pode realizar-se senão na perspectiva da complexidade das transformações do contexto. dentes deste processo é o avanço desordenado dos planos e seguros privados de saúde.

Já, no tocante à assistência pública à saúde, com a municipalização dos serviços, observa-se a tendência de uma atenção dirigida a comunidades e grupos populacionais, com prioridade para a proteção e a promoção da saúde, baseadas no trabalho com famílias e no atendimento domiciliar. Este modelo de assistência, que de longa data é defendido por diversos profissionais e intelectuais do campo da saúde, por ser mais eficaz e econômico, só agora vem sendo viabilizado pelo Estado. Entretanto, uma leitura mais aprofundada revela que, infelizmente, esta iniciativa na verdade não é fruto do interesse governamental em melhorar a saúde da população, mas da necessidade de se alcançar a configuração de "Estado mínimo".

Estas transformações, aliadas à contínua geração de conhecimentos científicos, tecnológicos e informacionais, bem como à consideração das diversidades culturais, étnicas e valorativas, vêm gerando desafios para a prática profissional do enfermeiro, uma vez que impõem novas exigências. Conseqüentemente, geram desafios também para a prática pedagógica das instituições e dos docentes responsáveis pela formação deste profissional.

A enfermagem, entendida como uma prática social, carregada de valores e contradições mas, sobretudo, de um compromisso com a emancipação humana para a vida e a saúde, não pode realizarse senão na perspectiva da complexidade das transformações do contexto social contemporâneo. No campo da produção de saberes em enfermagem, observam-se propostas que procuram subsidiar inovações na prática de cuidar/assistir no processo saúde/doença, o que sem dúvida contribui para ampliar os horizontes teóricos da enfermagem, uma vez que possibilitam nos aproximarmos de uma abordagem mais integral do ser humano em seu contexto. Mas, lamentavelmente, somos obrigados a

1 Mestre em Educação. Professora da àrea Saúde da Mulher. Coordenadora do Programa Interdisciplinar da Mulher - Universidade Católica de Goiás

${ }_{2}$ Mestranda em Saúde Pública. Professora da área Saúde Pública.

${ }^{3}$ Mestranda em Epidemiologia. Professora da área de Enfermagem Médico-cirúrgica.

${ }^{4}$ Doutoranda em Educação. Professora da área Saúde Pública. 
admitir que, para a maior parte da população, esta abordagem integral não está disponível, mesmo porque os serviços públicos freqüentemente não conseguem garantir nem mesmo um atendimento precário, ficando o cidadão e a cidadã sem nenhum atendimento.

Deste modo, não é difícil perceber que, o que ainda se sobressai como prioridade é a existência de profissionais comprometidos com a transformação das condições de vida e saúde da população. Para a realização desta tarefa, as novas perspectivas e novos saberes devem se fazer acompanhar de uma educação capaz de oferecer à sociedade profissionais cuja identidade seja carregada de elevada competência técnico/científica e ética, mas sobretudo de um sentido de emancipação social. Assim, a educação universitária deve estar preocupada em formar profissionais para uma sociedade que precisa ser reconstruída, com base nos princípios de cidadania e justiça social.

Bonafé (1995) afirma que um dos maiores paradoxos a ser enfrentado é que, diante de um processo de crescente mundialização econômica e cultural, a escola tem se ocupado em organizar mais ou menos de forma obsoleta, informações científicas e culturas fragmentadas, deixando escapar a oportunidade histórica de intervir na raiz dos problemas sociais e culturais em que deveria ter papel relevante. Neste sentido, consideramos que são essenciais as iniciativas para estabelecer a cooperação universidades/serviços/ações de saúde, objetivando o desenvolvimento do ensino, da pesquisa e da extensão, como forma de melhorar as condições de produção e utilização de conhecimentos e experiências, e, ao mesmo tempo, reafirmar o compromisso social da universidade e de enfermeiros/ enfermeiras, num projeto societário mais amplo e democrático.

Para Ângelo (1994) as instituições de ensino superior de enfermagem têm procurado desvendar caminhos que orientem suas ações para a formação do chamado profissional do novo milênio. Uma das possibilidades é o conceito de aprendizagem ativa, necessária para o desenvolvimento do pensamento crítico e de uma educação integral, em contraposição ao simples treinamento técnico. A educação em enfermagem deve possibilitar pensar, agir, saber, desejar, e buscar continuamente o conhecimento, questionar a verdade, apreciar os valores que a tornam uma atividade moral e humana. Esta educação requer um currículo como reconstrução social, a partir de uma abordagem crítica, que possibilite formar enfermeiros/enfermeiras cidadãos, para compreender e atuar no contexto políticosocial em que vivem. Nesta perspectiva, o Departamento de Enfermagem da Universidade Católica de Goiás (ENF/UCG), substituiu, a partir de 1997, o seu currículo. A nova abordagem visa preparar enfermeiros/enfermeiras para uma prática profissional cidadã, voltada para a promoção, proteção e recuperação da saúde, através de uma relação teoria/prática que propicie, também, intervenções diretas na comunidade local e regional, de forma transdisciplinar, mas capaz de resgatar e/ou resguardar a autonomia de saberes e práticas específicos de enfermagem.

A dificuldade de encontrar campos de estágios e práticas que permitissem desenvolver esta formação profissional, desencadeou no ENF/UCG uma série de discussões, que culminaram na proposta de organizar um campo de atuação docente/discente para subsidiar a nova proposta curricular, articulando ensino, pesquisa, estágio e extensão. Com a participação de professores, de membros da Comissão de Reforma Curricular e do Núcleo de Estudos e Pesquisas em Saúde e Sociedade (NEPSS), - ENF/UCG viabilizou a elaboração do projeto denominado "Enfermagem em saúde pública: uma proposta de assistência primária integrando ensino/pesquisa /estágio /extensão", com os seguintes objetivos:

- Promover maior integração entre o ENF/UCG e comunidade local e regional

- Propiciar aos futuros enfermeiros/enfermeiras a oportunidade de desenvolver práticas autônomas, resguardando a transdisciplinaridade de saberes do campo da saúde

- Organizar um banco de dados retroalimentador do planejamento e avaliação da assistência de enfermagem, bem como da produção científica discente e docente

- Contribuir para a elevação da qualidade de vida, do nível de saúde e da capacidade organizativa da população

- Implantar atendimento de enfermagem, individual e coletivo, domiciliar e institucional, de acordo com as necessidades de saúde da população. 


\title{
METODOLOGIA
}

\author{
OLOCAL
}

Optou-se por cinco bairros da região leste do município de Goiânia (Jardim Dom Fernando I, Jardim Dom Fernando II, Jardim das Aroeiras I, Jardim das Aroeiras II e Jardim Conquista), situados a $7 \mathrm{~km}$ do centro da cidade, com uma população de aproximadamente 15 mil habitantes. Esta escolha justifica-se pela carência da população e pela presença, nestes bairros, do "Projeto Meia-Ponte", desenvolvido pelo Instituto Dom Fernando (IDF). Este instituto, assim como a Universidade Católica de Goiás, é mantido pela Sociedade Goiana de Cultura, o que facilita a integração, representando uma soma de esforços, experiências e potencial, para ambas as partes. O Projeto Meia-Ponte tem por princípios apoiar iniciativas da comunidade que busquem melhorar suas condições de vida, educação, trabalho e saúde, pelo exercício da cidadania e da cooperação. Sua filosofia é representada pela metáfora da "meia-ponte", cuja construção exige o compromisso de ambas as partes: IDF e comunidade. O IDF já estava implementando com sucesso frentes de trabalho como a Cooperativa de Reciclagem de Lixo, o Centro de Educação Profissional, a Escola de Circo, o Horto de Plantas Medicinais, entre outras, necessitava incluir ações de saúde, para as quais convidou o ENF/UCG a se envolver. Sob o mesmo referencial da "meia-ponte", e ainda, tendo por objetivo atender às exigências do currículo em implantação, O ENF/UCG desenvolveu sua proposta de ação.

\section{DIAGNÓSTICO}

Em 1998, os alunos das disciplinas de Métodos e Técnicas de Pesquisa em Saúde e Enfermagem em Saúde Pública, foram capacitados para, sob a orientação e supervisão de professores, realizarem um diagnóstico através do Método de Estimativa Rápida, que indicou os seguintes problemas vividos pelas famílias da região:

- Escoamento insuficiente no período de chuvas, causando inundações e erosões.

- lluminação precária facilitando a ação de marginais.

- Falta de segurança.

- Uso e tráfico de drogas, inclusive por crianças.

- Acondicionamento inadequado e desprezo do lixo em entulhos, quintais, ruas, lotes, calçadas, córrego, e zonas de preservação ambiental.

- Acúmulo de água parada e caixas d'água mantidas destampadas.

- Transporte coletivo insuficiente ou ausente, com higiene e segurança precárias.

- Desemprego.

- Crianças deixadas sozinhas, em casa ou na rua.

- Unidade de saúde mais próxima apresentando filas, com grande tempo de espera; falta de médicos e outros profissionais; falta de medicamentos e materiais de consumo; relatos de óbitos de crianças por falta de atendimento.

- Ausência de ações ou atividades de saúde nas escolas. idade).

- Atividade sexual precoce (inclusive com relatos de ocorrência em menores de 9 anos de

- Morbidade e mortalidade: doenças respiratórias em crianças; doenças crônicas não transmissíveis; violência e acidentes de trânsito.

\section{SITUAÇÃO ATUAL}

No primeiro semestre de 1999 teve início a implantação do projeto. Os critérios para estabelecer prioridades foram, além dos problemas apontados pelo diagnóstico, a estrutura já existente no local (através do Projeto Meia-Ponte) e as necessidades curriculares do ENF/UCG. A primeira das prioridades foi promover a educação em saúde, compreendendo que isto significa realizar ações que possibilitam ao sujeito o desenvolvimento de um senso crítico em relação ao cuidado de sua própria 
saúde, assim como em relação à saúde como direito fundamental, que resulta de qualidade de vida de um modo geral e cujo alcance é uma obra coletiva. A seguir, apresentamos a descrição das atividades, de acordo com seu local de realização na comunidade.

\section{Centro de Educação Profissional Dom Fernando}

Neste Centro, são oferecidos cursos profissionalizantes para os desempregados, com vistas a melhorar suas chances de obter uma vaga no mercado de trabalho ou desenvolver o trabalho autônomo para geração de renda. São cursos de informática, pedreiro, cabeleireiro, manicura e pedicura, auxiliar de cozinha industrial, guia turístico, reparador de equipamentos, pintor, costura industrial, modelagem e eletricista. Em cada curso, além dos módulos profissionalizantes, foi introduzido um módulo de educação em saúde, contemplando os temas DST/AIDS, Higiene (pessoal, ambiental e mental) e Drogas. Além destes, de acordo com as profissões, foram oferecidas noções básicas sobre os riscos ocupacionais e saúde do trabalhador. Sob orientação e supervisão docente, os módulos foram planejados e desenvolvidos pelos alunos, em 28 cursos, com uma clientela de aproximadamente 600 pessoas. Este trabalho teve repercussão altamente positiva entre as famílias e se constituiu numa iniciativa inédita no município, em se tratando de cursos profissionalizantes.

\section{Núcleo Industrial de Reciclagem}

O Núcleo Industrial de Reciclagem (NIR) é mantido pelo trabalho em sistema de cooperativa (48 cooperados), membros das famílias da região. A renda gerada é dividida igualmente entre os cooperados. Utiliza como matéria prima o lixo desprezado pelas famílias da região através de coleta seletiva. O plástico reciclado torna-se matéria-prima e é comercializado com indústrias. Do papelão são fabricadas telhas, comercializadas no atacado e no varejo. Os metais e vidros são separados e vendidos.

Pela própria natureza do NIR, seus cooperados estão expostos aos vários tipos de risco ocupacional (físicos, químicos, biológicos, ergonômicos e de acidentes), sendo indispensável a prevenção dos mesmos. Por outro lado, diante do compromisso que a enfermagem deve assumir com a transformação da qualidade de vida e saúde da população, tudo o que se relaciona ao trabalho humano e suas consequências para a saúde, deve ser seu objeto atenção, visto que esta é uma atividade universal e indispensável à sobrevivência do cidadão, portanto, um problema de saúde pública. Assim, de acordo com as necessidades apontadas pelos próprios cooperados, nossa proposta de atuação no NIR abrange, inicialmente, o planejamento e implantação de um programa de promoção da saúde e prevenção das doenças, com os seguintes objetivos:

- Realizar, juntamente com a Comissão Interna de Prevenção de Acidentes, a identificação, avaliação e controle dos riscos ocupacionais presentes no NIR

- Promover a educação em saúde, objetivando a prevenção de doenças ocupacionais, assim como aquelas apontadas pelo diagnóstico da região;

- Promover atenção específica aos cooperados que executam atividades de alto risco

- Identificar sinais e sintomas dos cooperados e sua relação com o trabalho, auxiliando-os a reestabelecer sua saúde.

- Educação em saúde envolvendo os temas DST/AIDS, drogas e higiene.

A partir do primeiro semestre de 2000 o trabalho será extensivo aos demais membros das famílias dos cooperados, principalmente as crianças e adolescentes, abordando as dificuldades relativas à saúde, especialmente a prevenção de doenças e de gravidez na adolescência.

\section{Horto de Plantas Medicinais}

O elevado índice de desemprego e a perda do poder aquisitivo da população, somados ao aumento do índice de doenças, que definem o perfil das populações pobres em nosso país, também estão presentes em nossa região. Esta situação é agravada pela exploração capitalista da indústria farmacêutica, que vem inviabilizando, para a maior parte da população, a aquisição dos medicamen- 
tos necessários. Neste contexto, a fitoterapia tem se revelado uma alternativa terapêutica de baixo para doenças leves e moderados, além de ser um ótimo recurso preventivo, cujo uso guarda uma tradição popular histórica, e cujos conhecimentos podem ser aproveitados em prol da promoção da saúde e da prevenção de doenças.

Com a colaboração de membros da comunidade e sob a responsabilidade de uma farmacêutica e de um engenheiro agrônomo, encontra-se à disposição das famílias o Horto de Plantas Medicinais. Sua finalidade é fornecer matéria prima para a produção de medicamentos, oferecidos a um custo simbólico. Além dos medicamentos (chás, xaropes, pós, pomadas, etc.) também são produzidos sabonetes e xampus. Inicialmente, as atividades dos alunos no Horto abrangem a participação direta em todas as etapas do trabalho lá desenvolvido: identificação, cultivo, colheita, secagem e manipulação das plantas, bem como acondicionamento e distribuição da produção. O Horto oferece ainda a educação em saúde para crianças e adolescentes das famílias da região, da qual também passamos a participar com os temas DST/AIDS, drogas e higiene, além de outros.

\section{A Articulação Curricular - Ensino, Pesquisa, Estágio e Extensão}

O ENF/UCG está ativando a integração das disciplinas ao projeto, de acordo com os interesses curriculares, mas sem perder de vista as necessidades da população. Obviamente esta é uma articulação complexa e que impõe simultaneamente e de forma contraditória, exigências e limites, de ordem política, metodológica, teórica, filosófica, institucional, entre outras. Uma proposta desta envergadura exige altíssimo grau de responsabilidade e compromisso, pois envolve toda uma população, sua organização social, política, religiosa, cultural e todos os problemas daí decorrentes. Temos a consciência de que a integração curricular com as disciplinas e estágios, deverá ser efetivada de forma gradativa, cuidadosa, altamente responsável e comprometida, com profissionalismo e resguardando os princípios éticos e científicos.

Ciente de suas suas limitações, o ENF/UCG providenciou a qualificação de seu corpo docente, com vistas a subsidiar o projeto em andamento. Esta qualificação incluiu, além de uma política de pós-graduação (mestrado e doutorado), os seguintes cursos de atualização: Metodologia da Assistência de Enfermagem, Metodologia Científica e Programa EPIINFO.

Realizou-se também um diagnóstico quantitativo para traçar perfil epidemiológico da população da região coberta pelo projeto, constituindo-se um banco de dados, que já começou a ser disponibilizado, para a realização de pesquisas docentes e discentes, assim como para subsidiar as próximas etapas do desenvolvimento do projeto.

Além da continuidade do que já vem sendo realizado, estão previstas para serem iniciadas no ano 2000:

- atendimento domiciliar à gestante e à puérpera/recém-nascido.

- educação em saúde com as crianças e adolescentes da Escola de Circo.

- formalização de convênios com as Secretarias Municipal e Estadual de Saúde.

- elaboração do projeto de implantação de uma Casa de Parto.

- cursos profissionalizantes de higiene doméstica e babá.

- curso (não profissionalizante) destinado aos familiares que cuidam de seus idosos no lar.

\section{CONSIDERAÇÕES FINAIS}

O investimento na educação constitui um dos mais importantes meios para o aperfeiçoamento da prática de enfermagem, assim como para a melhoria de seu potencial de ação transformadora das condições de vida e da atenção à saúde da população. O contexto contemporâneo tem colocado em evidência o fracasso da atenção à saúde pública e a perplexidade dos profissionais de saúde, inclusive enfermeiros e enfermeiras, diante do aparecimento de doenças e epidemias, da incapacidade de controle das já existentes, da elevação da morbidade e mortalidade por determinadas doenças, a maioria preveníveis, etc.

É forçoso admitir que o processo de desconstrução/reconstrução do conhecimento, o 
redimensionamento das concepções de saúde/doença, homem/mulher, ambiente/natureza, cultura, existência, corpo etc., que estão nos fundamentos do saber e da prática de enfermagem, têm contribuído para revolver velhos fundamentos, submetendo-os à crítica e ao reconhecimento de suas limitações. Mas o que a realidade está indicando é que apenas isto não é suficiente para o redimensionamento da competência profissional de enfermeiros/enfermeiras, no sentido de que se constituam como sujeitos de transformação social. Não podemos permitir que o saber e a educação profissional em enfermagem caminhem no atendimento da nova profissionalidade exigida pela recomposição do capitalismo, ao invés de dirigir-se para o fortalecimento da profissão como prática social. Libâneo (1998) alerta que é insuficiente uma proposta pedagógica que se limite à crítica da educação existente sem oferecer possibilidades de modificar a prática pedagógica concreta. Cremos que a proposta pedagógica ora em desenvolvimento pelo ENF/UCG, busca prover ao futuro enfermeiro as condições para o atendimento às exigências profissionais da contemporaneidade, entretanto priorizando a promoção e proteção da saúde e a prevenção de doenças, propiciando a aquisição de ferramentas que Ihes possibilitam agir como transfomadores sociais, em parceria com as famílias, comunidades e outros profissionais. Isto representa um desafio e um exercício para ultrapassar o limite da crítica à educação em enfermagem.

\section{REFERÊNCIAS BIBLIOGRÁFICAS}

ANGELO, M. Educação em enfermagem: a busca da autonomia. Rev. Esc. Enf. USP, v. 28, n. 1, p. 11-4, abril. 1994.

BONAFÉ, J. M. El professorado en el tercer milenio. Cuadernos de pedagogía, n. 240, octubre, 1995.

LIBÂNEO, José Carlos. Adeus professor, adeus professora?: novas exigências educacionais e profissão docente. São Paulo: Cortez, 1998. 